\title{
Heróis e personagens - talvez sim, talvez ficção ${ }^{1}$
}

Moacy Cirne

Universidade Federal Fluminense

\begin{abstract}
A partir da Poeticidade Libertária, fundada na semiologia marxista e no imaginário bachelardiano, problematiza-se criticamente a concretude de personagens, sobretudo aqueles que se inscrevem no interior das histórias-em-quadrinhos. Estuda-se, assim, a cultura da paranóia e do narcisismo em Batman/Coringa, por exemplo. Mas se analisa também o humanismo de um Ken Parker. Relaciona-se o mundo dos quadrinhos com a linguagem do cinema e se propõe, no final, uma reflexão que, em sendo profundamente crítica, seja igualmente amorosa. Isto é, nos limites da Poeticidade Libertária.

Palavras-chave: Histórias-em-quadrinhos, Cinema, Semiótica, Poeticidade libertária.
\end{abstract}

Oersona, obra-prima de Ingmar Bergman, não é só um
belo filme, um dos mais belos de toda a história do
cinema (ao lado de $A$ aventura, de Antonioni): é um
filme que, em sendo metalingüístico, investe radicalmente na
concretude de personagens numa dada situação limite, em
termos conteudísticos, privilegiando o par loucura/transferên-
cia. Mas, antes de mais nada, neste caso específico - e daí a
sua elevada taxa estético-informacional no terreno da
metalinguagem -, um filme é um filme é um filme: a constru-
ção dos personagens (Elizabeth, atriz/Alma, enfermeira), com 
toda a sua densidade dramática e/ou psicológica, tem uma rigorosa estrutura interna que aponta para a estesia do próprio objeto fílmico. Com sua beleza expressional iluminada pela sensibilidade daqueles que o realizaram (diretor, atrizes, fotógrafo, etc..), Persona é um filme delicado como uma película que pode se partir ou se queimar.

A rigor, essa auto-referencialidade sígnico-simbólico (afinal, o filme se coloca inteiro para o espectador, a partir de sua materialidade específica) faz com que amemos Persona como um valioso cristal que, jóia rara, paradoxalmente não deveria ser partido, não deveria ser quebrado. Partidos são os seus personagens principais. Contudo, segundo a brilhante análise de Susan Sontag, "para compreender Persona, o espectador deve ultrapassar o ponto de vista psicológico. ... Persona assume uma posição além da psicologia - assim como, num sentido análogo, além do erotismo" (Sontag, 1987, p. 127-8). Isso se dá justamente porque o discurso do filme enquanto cinema termina mobilizando/agenciando a própria ossatura cinematográfica: o iluminamento de suas imagens, a narrativa que monta e desmonta o conteúdo da trama, a já citada tessitura metalinguiística que funciona como um processo de distanciamento crítico-amoroso entre o espectador e o objeto fílmico em si. Por outro lado, esta particular metalinguagem tem origem, como fonte e material de trabalho, em lembranças de infância do próprio Bergman (1996, p. 55). Mais do que isso, o que norteia - enquanto necessidade criativa - o mundo de Bergman? Como se plasma o seu universo de signos e símbolos teatrais e cinematográficos?

A criação artística em mim manifesta-se sempre como um tipo de fome. Foi com grande satisfação que constatei esta minha necessidade, embora em toda minha vida nunca tenha perguntado como é que tal fome surgiu, nem exigi terminantemente satisfazê-la. Nestes últimos anos, quando ela começou a diminuir, sinto que é urgente esclarecer os motivos de minha atividade (Bergman, 1996, p. 48).

Poder-se-á dizer que Bergman não é o único grande artista angustiado pela fome de criação; a história da arte, da mú- 
sica, do teatro, da literatura, da poesia, do cinema está repleta de seres angustiados com o seu processo de criação.

\section{E a história dos quadrinhos?}

A resposta virá mais tarde; precisamos investir em outras vertentes críticas. De qualquer maneira, é preciso ficar bem claro, a nossa praia teórica é o campo da poeticidade libertária, e não o da Psicologia ou da Psicanálise. E o que vem a ser a Poeticidade Libertária? É o campo crítico que incorpora elementos de uma possível semiologia marxista, do realismo semiótico ${ }^{2}$ e do imaginário bachelardiano, além de uma poética libertária a partir do poema/processo: uma poeticidade que evita a "leitura inerte" (cf. Bachelard) para se pensar através da "leitura produtiva" (cf. teoria e prática do poema/processo). ${ }^{3}$ Em última instância, estaríamos diante de uma leitura que problematiza politicamente o objeto estudado. Isto é, que procura se aproximar desse ou daquele objeto (estético, literário etc..) passando por mediações construídas a partir da relação texto/contexto no interior do conjunto relacional razão/emoção.

Em outras palavras: a Poeticidade Libertária por nós sugerida entende o contexto, tomado poeticamente, como determinante do texto, tomado politicamente, só que não o faz de forma mecanicista, já que pressupõe uma leitura produtiva (longe de reduplicações ideológicas) aberta às múltiplas significações de cada obra-de-arte. E assim como não existe leitura inocente (cf. Althusser), não existe crítica inocente: a nossa própria leitura carrega, claro, algumas marcas fundantes do marxismo. Só que estas marcas - historicamente falando - são necessárias. Crítica e produtivamente necessárias. Mas, decerto, não são as únicas marcas. Outras (Bachelard, poema/processo, sobretudo) persistem em nossa travessia literária, em nossas veredas ensaísticas. Através delas, em busca de uma militância desejante em relação às atividades crítico-criativas do nosso universo produtivo, procuramos problematizar a compreensão que temos do mundo e da arte. E, para nós, problematizar significa questionar, duvidar, criar problemas, em suma, basicamente preocupados com 
perguntas e não com respostas. "Duvido, logo penso", poderíamos afirmar, parafraseando Descartes. E se duvidamos, questionamos; se questionamos, problematizamos.

Diante de filmes como Persona (Bergman) e L'avventura (Antonioni) não podemos trabalhar com modelos operatórios rígidos. Diante de discos como A love supreme (Coltrane) e Memórias chorando (Paulinho da Viola) não podemos cair nos equívocos de um formalismo estéril. Diante de livros como $A$ invenção de Morel (Casares) e Ficções (Borges) não podemos ignorar os labirintos do imaginário semântico.

Será que a crítica também deve ser sonhadora?

Voltemos à questão inicial, até então apenas implícita: como se dá no espaço significante da arte e da literatura, a real concretude dos personagens. E mais ainda: como se elabora a sua importância na formação artística.

Seria o personagem, com sua ontologia ficcional, um problema epistemológico? O crítico Anatol Rosenfeld acredita que sim. Com ele, problema entre problemas, a ficção se torna mais nítida, mais clara, assim como através dele "a camada imaginária se adensa e se cristaliza"(Rosenfeld, 1995, p.21). Isto não quer dizer que os traços ficcionais do romance, da novela ou do conto não se definam para além dos personagens, mas, com eles, o tecido literário pode se constituir com mais sentido formal (Rosenfeld, 1995, p. 27): a chama que, bruxuleante, ilumina a ficção. Tomemos aliás, a metáfora da chama. Certos personagens (Diadorim, em Grande Sertão: veredas, por exemplo) requerem a luminosidade poética, vacilante, da pequena chama de uma vela ou de uma lamparina. Citemos, pois, Bachelard, entendendo aqui, a citação como o lugar de um desejo manifesto, que se quer crítica (reflexão) e criação (paixão):

Entre todas as imagens, as imagens da chama - das mais ingênuas às mais apuradas, das sensatas às mais loucas contêm um símbolo de poesia. Todo sonhador inflamado é um poeta em potencial. Toda fantasia diante da chama é uma fantasia admiradora. Todo sonhador inflamado está em esta- 
do de primeira fantasia. Esta primeira admiração está enraizada em nosso passado longínquo. Temos pela chama uma admiração natural, ouso mesmo dizer: uma admiração inata. A chama determina a acentuação do prazer de ver, algo além do sempre visto. Ela nos força a olhar (Bachelard, 1989, p. 11).

Basta ver, com sensibilidade, certas configurações mitológicas que plasmam alguns personagens para que entendamos melhor o espaço epistemológico de sua concretude: ora é um Carlitos que faz de Chaplin um dos gênios do cinema ${ }^{4}$, ora é um Dom Quixote que ilumina a obra de Cervantes, ora é um Robinson Crusoé que tipifica o herói-aventureiro de Daniel Defoe, ora é um Riobaldo que não assume a usa homossexualidade em Guimarães Rosa. Basta ver, com olhos livres, a construção ficcional de Capitu, em Machado de Assis; a de Hans Castorp, em Thomas Mann; a de Joseph K., em Kafka; a de Meursault, em Camus. A de Elizabeth/Alma, em Bergman. Ou a de Batman/Coringa, nos quadrinhos de Alan Moore \& Brian Bolland e Grant Morrison \& Dave Mackean.

Ver com olhos livres, antropofagicamente, sem preconceitos. Como em Oswald de Andrade. Só assim não nos escandalizaremos com a inclusão do par Batman/Coringa ao lado de outros grandes personagens da história da literatura e do cinema. De qualquer maneira, dentro de um perspectiva de poeticidade libertária, não há lugar para o preconceito, não há lugar para a exclusão: mais do que estética, a nossa é uma crítica decididamente cultural. Embora saibamos que, em se tratando de quadrinhos, a história dos personagens mereça um olhar crítico antenado com os mecanismos ideológicos da indústria cultural: a própria especificidade dos comics resolve-se num espaço gráfico-narrativo que, teoricamente, pode dispensar ou amenizar o "estar-dramático" dos personagens, sejam heróis ou não.

Aliás, será que, nos quadrinhos, um personagem para se realizar plenamente precisaria ser um "herói", com todas as consequiências ficcionais e mitológicas que tal fato acarreta? Mas, antes de mais nada, o que vem a ser um herói? Maria 
Rita Kehl parte de Pierre Fédida para, superando-o, pensar o cinema americano no interior das "culturas do narcisismo" (Kehl, 1996, p. 108-10) ${ }^{5}$. Em Fédida, segundo Kehl, o herói seria "aquele que se destaca da massa para praticar um ato fundador da civilização - o assassinato do pai primitivo - e depois voltar para anunciá-lo, "para inscrever o mito na linguagem'. Este herói é portanto, também, um poeta” (Kehl, 1996, p. 108). A própria Kehl assinala que esta é uma leitura bastante singular do mito elaborado por Freud em Totem e Tabu. O que interessa aqui, sobretudo para nós, é problematizar o herói solitário que, com sua neurose extremamente obsessiva, paradigma do perseguidor/perseguido ${ }^{6}$, constrói em torno de seus fantasmas aquilo que é nomeado por Maria Rita Kehl como "o imaginário da paranóia" (Kehl, 1996, p. 110). Neste sentido, nada mais paranóico do que os mundos narcisisticamente delirantes do Super-Homem e do Batman, por exemplo. São mundos que promovem a "cultura do narcisismo" em sua vertente psicológica mais exarcebada.

Decerto, há os heróis épicos, com toda a sua dimensão trágica: uma dimensão que, em sendo demasiadamente humana, aposta na possibilidade utópica, sonho entre os sonhos, de se construir, no Homem, a sua história (Kothe, 1987, p. $15)^{7}$. Tal qual, de certa maneira, pensavam os existencialistas, Sartre à frente: estamos condenados a construir o nosso próprio destino. Só que, sabemos muito bem, existem instâncias econômicas, políticas e culturais que, direta ou indiretamente, podem sobredeterminar o nosso modo de vida. A não ser que sejamos um Surfista Prateado, o herói quadrinhístico de Stan Lee, condenado a viver para sempre no planeta Terra, quando, marcado pela radicalidade existencial, não compreende e/ou não aceita os seus valores morais e culturais. Claro, mais do que nunca é preciso aceitar as diferenças, é preciso entender o Outro. Diremos mais: pelo menos em arte, comunicação e literatura, é preciso estimular as transgressões. Pensemos bem: o que seria do cinema sem as inovações \& transgressões semióticas de Vertov, Keaton, Welles, Resnais, Godard e Glauber Rocha? Ou, de forma mais ou menos paralela, o que seria do mesmo cinema sem a maestria 
cinefenomelógica de Eisenstein, Renoir, Ford, Huston, Bergman e Antonioni $?^{8}$ Ou, no primeiro caso, Bressane, Sganzerla, Tonacci, Luiz Rosemberg Filho; no segundo, Vladimir Carvalho, Sérgio Santeiro e Nelson Pereira dos Santos? Geralmente dionisíacos, quando inventores, geralmente apolíneos, quando mestres, os cineastas (e demais criadores) fazem arte plasmando um sistema de bens simbólicos e culturais antenados com o social e o real nosso de cada dia. Caso contrário, ter-se-á apenas uma arte estéril, sem maiores consequiências produtivas. Contudo, é bom esclarecer: uma arte antenada com o social e o real não significa, necessariamente que ela tenha que responder de modo direto às exigências $\mathrm{e}$ implicações do seu tempo. O diálogo que um dado artista ou escritor/poeta estabelece com o tempo que o envolve é um diálogo capaz de provocar múltiplas respostas (a partir de todas as dúvidas do mundo!); não pode ser um "diálogo" de surdos, mudos e cegos.

Há outros "heróis", como os heróis nacionais. Na maioria das vezes, em nosso século, são "heróis" fabricados pela mídia. Inclusive, pela mídia esportiva. Aqui, são muitos os desvios jornalísticos que levam a uma verdadeira banalização da figura do "herói". Para esta mídia alimentada pela paranóia mercadológica e pelas frustrações patrioteiras de uma nação, qualquer competição esportiva termina sendo o campo possível para se demonstrar a quintessência do "heroísmo". Do mesmo modo diremos que existe uma crítica de quadrinhos que faz da apologia do super-herói ou do herói Disney, ambos americanos, a sua razão de ser: uma razão muito pouco criativa, convenhamos.

"Os personagens de HQ existem apenas para viverem intensamente"(Fresnault-Deruelle, 1980, p. 125). A citação de Fresnault-Deruelle coloca a questão de forma correta, o que serve para levantar vários problemas semióticos. "Este é, com efeito, o destino deles (os personagens), pois só aparecem em função do recorte seletivo de um cartoonist decidido a pôr em cena apenas os momentos que importem. As relações interpessoais, reduzidas ao essencial, às vezes mesmo exarcerbadas, tecem assim um micro espaço específico das 
HQ" (p. 125), acrescenta o semiólogo francês. Dentro dessa perspectiva, não existiria nos quadrinhos o "tempo morto" (tão importante no cinema de Antonioni, por exemplo), assim como não haveria "espaço vazio" (p. 126). A questão colocada por Fresnault-Deruelle exige duas reflexões sobre a matéria, no mínimo: (1) os quadrinhos não admitem, enquanto linguagem, a possibilidade de um "tempo morto" ou de um "espaço vazio"? e (2) em assim sendo, os quadrinhos - ao deslocarem o papel dos personagens para um dado subtexto diluidor de sua concretude - não perderiam importância ficcional?

Em relação ao primeiro ponto, afirmaremos que, embora raros, o "tempo morto" e mesmo o "espaço vazio" podem encontrar um lugar significante nas histórias-em-quadrinhos: um lugar que se marca pelo agenciamento narrativo. Decerto, assim como o cinemão americano repele qualquer possibilidade de tempo morto/espaço vazio, os comics também o fazem. Só que, mesmo raros, repetimos, podem aparecer nos quadrinhos. E com intensidade narrativa, se for o caso.

Como numa estória de Ken Parker, de Giancarlo Berardi \& Ivo Milazzo, publicada na Itália em 1984 e editada no Brasil dez anos depois (1994, p. 84). Curiosamente, trata-se de um bangue-bangue não americano marcado pela espessura existencial de seu personagem. A bem da verdade quadrinhística, Ken Parker quer nos parecer o melhor bangue-bangue de todo o quadrinho: a "humanização" de suas estórias atravessa a saga do oeste americano com rara inteligência conteudística. Sem a grandiloquência formal de um John Ford, por certo. Mas se Ken Parker não é um John Wayne (aliás seu tipo físico lembra o ator Robert Redford), não é um personagem qualquer, não é um herói qualquer: ele é a síntese de um saga que não se esgota na simples tipificação do desbravador ianque. Diríamos que ele é um herói "politicamente correto", embora, muitas vezes, esta expressão apenas revele o "politicamente chato". Contudo, este não é o caso de Ken Parker. Há em suas estórias mais verdade humana do que na maioria dos filmes e quadrinhos que se voltam para o mundo do faroeste.

A história em questão é Os cervos. Mas antes de falarmos no "tempo morto" que, num determinado momento, vai norteá- 
la, falemos na poesia que a domina, salientando que se trata de uma estória de corte ecológico no sentido mais amplo possível da palavra. E pensar a poesia, aqui, significa pensar a poesia em estado de abstração emocional. Não estamos diante de um poema, evidentemente, mas estamos diante do mesmo grau de poeticidade subjetiva que marca as obras, entre outros, de Chaplin, Tati, Fellini.. Existe, em Os cervos, o sentimento de um real poético fora da textualidade sígnica que dá corpo a este ou àquele poema real. A poesia atravessa a obra através de um particular código de referências gráficas e humanísticas; é uma poesia para ser sentida, mais do que para ser experimentada enquanto concreção.

Em não sendo um poema - a não ser que o vejamos na categoria pouco precisa de poema quadrinhesco, Os cervos é um quadrinho (sem palavras) da melhor qualidade estéticoinformacional. São vinte páginas, precedidas de uma páginaapresentação e de uma página-epígrafe, que, aliás, dá o tom lírico de toda a saga de Ken Parker:
Deus dorme
nas pedras
Respira
nas plantas
Sonha
nos animais
Desperta
no homem.
(Poesia índia)

Por mais estranho que possa parecer (para os menos avisados), em se tratando de bangue-bangue, há um certo toque feminino em Os cervos: a feminilidade não está nas expressões do personagem, claro, antes está na maneira intimista de se ver o mundo. O grafismo aquarelístico do desenho concorre para que, com o personagem, celebremos a natureza: as cores esmaecidas completam a sensação de paz e tranqüilidade. Gráfica e plasticamente, a estória, em sendo uma celebração elegíaca da natureza, é uma pequena obra-prima como 
realização poético-quadrinizante. Fluente, porém contida, a estória de Berardi \& Milazzo apresenta todos os elementos de uma narrativa escrita com rigor: cortes precisos, enquadramentos funcionais, cores adequadas, conteúdo inteligente. Completemos, então, localizando, agora, o seu "tempo morto".

Será nas páginas 8 e 9 da estória (18 e 19 do álbum) que ele vai aparecer. Nelas, o tempo narrativo é mínimo a ação quase "desaparece". Nas duas páginas em tela, treze imagens dão conta da seguinte cena: o cervo-fêmea, ferido (na fuga pela sobrevivência), encontra-se entre seus filhotes. Quando, então, o nosso herói o vê, de arma na mão: este é o momentochave. Numa das páginas, a quinta imagem capta o olhar do cervo; na outra, igualmente a quinta imagem capta a expressão de Ken Parker. O olhar do cervo: interrogativo; a expressão de Ken Parker: preocupante. É preciso salvar o cervo: há vida (os três filhotes), naquela floresta em pleno inverno, que necessita de proteção e de carinho materno. Nestas treze imagens, nada acontece e tudo acontece. Parker estava visivelmente faminto; precisava caçar para sobreviver. Os quatro estão indefesos diante de sua mira, diante de seu olhar. O tempo de leitura também parece ficar suspenso no ar. Os filhotes lambem a ferida da mãe. Silêncio absoluto; a selva selvagem está muda. Este é um quadrinho de poucos ruídos, de poucas onomatopéias (um estalido no início; três estampidos quase no final). O leitor prepara-se para o corte gráfico maior : lentamente, viramos a página (da ímpar para a par).

Podemos continuar os nossos devaneios: a "viagem" de Berardi \& Milazzo permite que também viajemos. $\mathrm{O}$ gelo em torno daqueles personagens, na solidão da floresta, com a tensa situação criada, abre espaços para alguns devaneios, para algumas simbologias de vida e morte, de ação e repouso. Não foi por acaso: afirmamos, antes, que havia um certo toque de feminilidade em Os cervos. Este toque estava presente na maneira intimista (de ver o mundo) e na grafia aquarelística (do desenho). Assim como está na idéia de devaneio, na idéia de repouso. Voltemos, pois, a Bachelard, sempre Bachelard: 
Os melhores dos nossos devaneios procedem, em cada um de nós, homens ou mulheres, de nosso ser feminino. Trazem a marca de uma feminilidade inegável. Se não abrigássemos em nos um ser feminino, como haveríamos de repousar? (Bachelard, 1988, p. 89).

O leitor, então, lentamente se prepara para mais um corte gráfico: viramos a página. $\mathrm{O}$ devaneio continua: Parker decidira cuidar do animal. Em ritmo de "câmera lenta" (pós-"tempo morto") a estória se desenvolve, até o final, talvez cruel, talvez amargo, com a presença indígena como contraponto temático. Aqui também os dados estavam jogados. Solitário, no melhor estilo do bangue-bangue clássico, o herói parte; novas aventuras (intimistas?) o aguardam, com certeza. Há qualquer coisa de frágil em sua masculinidade, mesmo com toda a carga de virilidade possível. Será Ken Parker um grande personagem (dramaticamente falando), um grande herói (mitologicamente pensando)? Talvez sim, talvez pura ficção. Mas ficção de quem, ou de quê? De nossa Poeticidade Libertária? Da própria ficção - e neste caso estaríamos diante de uma metaficção? Ou a Poeticidade Libertária é simplesmente uma metacritica, aberta às viagens delirantes de qualquer imaginação mais sofisticada? Talvez sim, talvez ficção, talvez pura crítica. O que não nos impede de afirmar, criticamente: Ken Parker é um dos grandes momentos criativos das estórias-em-quadrinhos. E Os cervos contêm uma alta dose de poesia.

Falta determinar, agora, a segunda reflexão levantada pela postura teórica de Fresnault-Deruelle (sabendo-se que ainda seria possível encontrar outros preciosos "tempos mortos", em particular nos quadrinhos produzidos depois dos anos 60). Que reflexão?, perguntar-se-á. Ora, a "banda desenhada", ao deslocar o papel dos personagens para um dado subtexto diluidor de sua concretude (conforme já foi dito), não perderia importância ficcional?

Se os personagens realizam-se apenas para viverem com intensidade o recorte seletivo da cena narrada, ou seja, se eles, como salienta Fresnault-Deruelle, "estão condenados a man- 
terem entre si uma comunicação física e verbal quase permanente" (1980, p. 126), o mundo ficcional dos quadrinhos - de acordo com o argumentista/roteirista -, independente da maior ou menor presença dos "atores", concretiza-se no interior da linguagem: afinal, mais do que no cinema, mais do que na literatura, mais do que no teatro, o bom quadrinho implica uma exigência narrativa que extrapola a própria presença dos personagens. Precisemos melhor: os quadrinhos são criativos e merecedores do nosso respeito artístico e intelectual não pela possível profundidade (filosófica, literária, "humana" etc.) desse ou daquele personagem, mas por uma série de procedimentos semióticos no cerne da própria linguagem quadrinhística. Não nos esqueçamos: a especificidade dos quadrinhos passa por uma particular narrativa gráfico-visual, com os cortes espácio-temporais que a impulsionam e a alimentam semioticamente. Tanto é que os heróis mais "profundos" das HQs - um Bernard Mergendeiler ${ }^{10}$, um Krazy Kat ${ }^{11}$, um Charlie Brown (Eco, 1970; Short, 1968), um Homem-Aranha ${ }^{12}$, um Corto Maltese ${ }^{13}$, entre outros -, com exceção do feifferiano Mergendeiler, talvez não resistam a uma crítica mais acurada ou mais complexa. Nem por isso os quadrinhos deixam de ser um discurso estético-semiológico extremamente significativo, seja como indústria cultural (na maioria dos casos), seja pura e simplesmente como discurso artístico. Afinal de contas, para nós, entre as maiores obras estético-narrativas do século figuram quatro ou cinco filmes (L'avventura, Persona, A regra do jogo, Ano passado em Marienbad, Cidadão Kane), seis ou sete obras literárias (Grande sertão: veredas, A montanha mágica, Ulisses, $O$ processo, $A$ invenção de Morel, Billennium, Vidas secas). E três ou quatro quadrinhos: The Spirit, Little Nemo, Krazy Kat, Corto Maltese.

Aliás, faz parte da própria estrutura quadrinhística o papel expressional do personagem. A rigor, um grande personagem de quadrinhos tem de ser grande, antes de mais nada, no interior dos quadrinhos, com uma tensão/pulsação adequada à linguagem que o formaliza enquanto herói, anti-herói, marginal, etc. Assim, grandes são Mergendeiler, de Feiffer, e Galileu, de Ziraldo; Krazy Kat, de Herriman, e a Graúna, de 
Henfil; Spirit, de Eisner, e Madame e seu Bicho Muito Louco, de Fortuna; Corto Maltese, de Pratt, e Dr. Macarra, de Carlos Estévão. Os exemplos multiplicar-se-iam: Valentina, de Crepax; Little Nemo, de McCay; Mr. Natural, de Crumb; Snoopy, de Schulz; Ferdinando, de Capp; Philémon, de Fred; Cocco Bill, de Jacovitti; Paulette, de Wolinski \& Pichard; Pogo, de Kelly; Ken Parker, de Berardi \& Milazzo; Rê Bordosa, de Angeli; Mafalda, de Quino; Demolidor, de Lee; Fantasma, de Falk \& Moore; Geraldão, de Glauco; Dr. Baixada, de Luscar; Batman, de Bob Kane.

\section{Batman.}

Batman. Um nome para se pensar.

Não que seja um dos melhores quadrinhos; contudo há no personagem problematizações emblemáticas que merecem ser discutidas. Há o personagem em si e há, como já vimos, a sua relação com o marginal Coringa, um dos principais bandidos gerados pela indústria cultural. Voltemos à questão do "estardramático", assim como à questão de saber se um personagem, para se realizar de forma plena, precisaria ser "herói". No primeiro caso, procuramos mostrar que o "estar-dramático", para os quadrinhos, é algo relativo: um bom quadrinho independe de sua concretização como tal. No segundo caso, basta citar Fritz the Cat, de Crumb, modelo de anti-herói (assim como os anti-heróis de Feiffer), para que repensemos a questão dada. Há mais: Coringa, marginal assumido, é um personagem plenamente realizado dentro dos meandros criativos das HQs. Voltemos, aqui e agora, a falar de Batman. Ou melhor, voltemos a falar de Batman/Coringa.

Batman, um nome para se pensar. Sua origem é conhecida: uma resposta mercadológica à saga de Super-Homem, já em 1939 (Super-Homem fora lançado em 1938). Criado por Bob Kane, o Cavaleiro das Trevas, ao contrário do seu "colega" de aventuras super-heróicas, sempre teve bons desenhistas: Jerry Robinson (entre 1939 e 1946), Bill Elder, Carmine Infantino, Jim Aparo, Neal Adams e outros, entre os quais, mais recentemente, de forma gloriosa, Frank Miller. Coringa, o mais famoso dos marginais do universo batmaníaco, foi uma criação de Jerry Robinson. De bufão do crime a psicopata 
ensandecido, a trajetória de Coringa, redimensionada por Frank Miller, Alan Moore e Grant Morrison (em O Cavaleiro das Trevas, A piada mortal e Asilo Arkham, respectivamente), a partir de indicações, nos anos 70, concebidas por O'Neil \& Adams, termina por ter mais consistência dramática do que a de muitos personagens heroizados das HQS. "A origem de Coringa não é a de um criminoso, coisa que ele, afinal, já era (embora $A$ piada mortal nos remeta à outra fonte inicial), mas a de um psicopata. Esta sua concepção como psicopata não era evidente em suas primeiras aparições. $O$ maníaco pelo menos se preocupava com o dinheiro do assalto ou do roubo. Também era mais capacitado a lutas corporais do que veio a ser em versões posteriores" (Baptista, 1993, p. 71). Veja-se $A$ piada mortal (cujo título original é mais expressivo: The killing joke). Sem dúvida, em sua loucura, Batman e Coringa são faces de uma mesma moeda: neste sentido, a última sequiência da trama é exemplar. Há um beco sem saída na relação dos dois; claramente, Batman quer ajudá-lo ("Podíamos trabalhar juntos. Eu podia reabilitar você. Não precisa ficar alienado de novo. Não precisa ficar sozinho. / Não precisamos nos matar. / O que diz?"). Existe, aqui, alguma coisa de patético. E a expressão de Coringa, derrotado, revela mais do que o desespero, revela a possibilidade da superação, na medida em que ele, humanamente, sabe das fraquezas e das reticências do Outro. Afinal, Batman seria realmente um inimigo?

E se houvesse uma relação homossexual entre os dois? Esta hipótese já foi levantada por alguns estudiosos, inclusive pelo roteirista brasileiro Carlos Eugênio Baptista [Patati], na sua Dissertação do Morcego (1993). Sem dúvida, para o estreito mundo dos super-heróis, e para a formação da psicologia de personagens quadrinhísticos, é uma hipótese fascinante, muito mais do que a possível homossexualidade entre Batman e Robin, por exemplo. Neste particular, Asilo Arkham e $A$ piada mortal teriam algumas indicações preciosas. Mas, é necessário que se diga que o universo de qualquer superherói não pode se resumir a duas ou três estórias: são múltiplos os roteiristas, são múltiplos os desenhistas que alimentam uma saga. São múltiplas as aventuras ( \& desventuras) 
que fazem o mundo de Batman. Mesmo assim, há estórias que ficam mais do que outras, que marcam mais do que outras. Decerto, A piada mortal e Asilo Arkham são grandes exemplos de estórias que marcam e definem um personagem, aparentemente já definido. Assim como marcante fora $\mathrm{O} \mathrm{Ca}$ valeiro das Trevas.

A relação Batman/Coringa, em sendo homossexual, causaria um grande impacto, sem dúvida. E se Batman sempre foi um personagem mais interessante do que o insosso SuperHomem, esta revelação, se confirmada, abriria algumas portas da imaginação que o tornariam ainda mais razoável (no mundo dos quadrinhos), não pela homossexualidade em si, um comportamento sexual como outro qualquer, mas pelo componente desviante que, neste caso, romperia com o par dicotômico ordem/desordem, sendo Batman a Ordem, isto é, a Lei, e Coringa, a Desordem, isto é, a Marginalidade. Se em A piada mortal os dois terminam unidos, no fim, pela mesma piada e pela gargalhada comum, em Asilo Arkham há, de modo explícito, o autoquestionamento que faz com que Batman, antes de mais nada, tenha consciência de sua possível loucura: indagado sobre se tinha medo de entrar em Arkham, momentaneamente revoltada sob a liderança de Coringa, o Homem-Morcego se deixa levar por uma longa reflexão ("Medo? / Batman não tem medo de nada. // Sou eu. É de mim que tenho medo./ Medo de que o Coringa esteja certo sobre mim./ Às vezes, eu questiono a racionalidade das minhas ações. // Estou com medo de que, quando atravessar os portões do asilo.../ ...quando eu entrar no Arkham e as portas se fecharem atrás de mim.../ vai ser como voltar pra casa"). Em termos de importância - para as coordenadas temáticas do Batman - este monólogo lembra um outro, no final dos anos 60, em plena guerra do Vietnã, colocado não pelo Cavaleiro das Trevas, mas pelo Capitão América: “... eu deveria ter lutado menos e perguntado mais".

Naquela época os super-heróis que se questionavam eram os de Stan Lee: Homem-Aranha, Surfista Prateado, Quarteto Fantásico, o novo Capitão América. Se bem que, simultaneamente, a verdadeira revolução gráfica e temática se dava 
através de Crumb, Shelton, Moscoso, criadores dos comix underground, uma porrada na moral norte-americana, de acordo com os anseios da contracultura. Para muitos de nós, o sonho acabou, assim como acabou a contracultura. Mas a idéia (talvez utópica) de um quadrinho inteligente continua viva, e respira através de obras as mais diferentes e imprevisíveis. $\mathrm{O}$ Cavaleiro das Trevas, A piada mortal e Asilo Arkham entre elas. Não é por acaso que Grant Morrison recorre a Lewis Carroll para pôr uma epígrafe em Asilo Arkham:

"Mas eu não quero me encontrar com gente louca", observou Alice.

"Você não pode evitar isso", replicou o gato.

"Todos aqui somos loucos. Eu sou louco. Você é louca".

"Como sabe que sou louca?", indagou Alice.

"Deve ser", disse o gato, "ou não teria vindo aqui".

(Alice no País das Maravilhas)

Aliás, Morrison volta a citar Lewis Carroll no fim de $A s i$ lo Arkham. Ao que parece, só a loucura seria capaz de salvar Batman de seus pesadelos. Esta parece ser uma direção razoável não só para o Homem-Morcego, mas para qualquer herói mascarado. A máscara, afinal, tem um forte componente psicológico; suas origens remontam à tragédia grega. Mas Batman e os demais super-heróis não têm a consistência dramática do teatro clássico, é claro. Aliás, nunca pretenderam tê-lo. São outras as diretrizes criativas das histórias-em-quadrinhos, já o vimos. De qualquer maneira, há algo de trágico neste Batman entre a dor e loucura. Será que, referindo-se a Faulkner (em Palmeiras Selvagens), ele poderia afirmar: "Entre a dor e a loucura, eu prefiro a loucura"? Decerto, entre a dor e o nada, Batman preferia a dor. Pelo menos, este Batman redimensionado por Miller, Moore e Morrison. Coringa, também, evidentemente. Os dois se completam, na mesma loucura e na mesma sexualidade. Os dois se completam, na mesma tensão psicológica. 
"Se não é possível resolver contradições, pelo menos podese usar produtivamente umas contra as outras: as contradições de nossas contradições não se transformam necessariamente em nossas aliadas, mas alteram as regras do jogo de maneira tão certa como o próprio Tempo, quando ele faz os problemas que enfrentamos se empinarem como os flamingos de Alice e tomarem uma forma inesperada", afirma Fredric Jameson (1994, p. 95). Por certo, não somos pós-modernistas (nem pós-vanguardistas, bem entendido). Mas, sem dúvida, quando pensamos no par Batman/Coringa, pensamos em contradições conteudístico-psicológicas que podem ser produtivamente usadas umas contra as outras, embora nada resolvam no campo em si da contradição pura e simples. Aqui, as contradições se atraem; fazem parte de um mesmo jogo semântico e formal. A fusão perseguidor/perseguido se dá sem a necessidade da transferência. Como em Persona, ultrapassemos o ponto de vista psicológico. Só que não podemos cair nas facilidades do ponto de vista sociológico. Por isso, procuramos investir criticamente na Poeticidade Libertária, embora o pensamento marxista, por si só, pudesse servir de modelo teórico para embates ideológicos e produtivos no terreno da arte e da literatura. E dos quadrinhos, naturalmente. Tudo vale a pena, se o desejo não é pequeno. Parafraseando Fernando Pessoa, estamos querendo dizer apenas o seguinte: como a arte, a crítica também é fruto do desejo. Propomos uma crítica amorosa - mas não submissa - para objetos sensíveis. Propomos uma crítica amorosa, sim, para aqueles produtos estético-informacionais que merecem ser amados. Que merecem ser analisados historicamente.

Dizíamos, antes, que a história da arte está repleta de criadores angustiados. A angústia - de cunho pessoal e/ou político-social - termina sendo, para muitos, o motor de suas experiências estéticas mais radicais. E na história dos quadrinhos? Como na história do cinema, em menor grau, em função da mesma operacionalidade gerenciada pelos mecanismos da indústria cultural. Aliás, menos do que no cinema. Nos quadrinhos, não encontramos ninguém com a estatura existencial de um Antonioni, de um Bergman, de um 
Tarkovski. Mas isso, para a história dos discursos artísticos e literários, a rigor, é secundário. Ou, pelo menos, deve ser relativizado. O que importa, em última instância, é a obra enquanto tal, pensada no interior das problematizações sociais, históricas e culturais. E mais ainda: pensada como um sonho estético (ou anti-estético). Como um sonho a partir de significantes adequados, ou seja, a partir de elementos constitutivos inerentes à própria organização artística ou literária. Assim, sonhamos com esta ou aquela dada manifestação criadora. Desde que saibamos ser sensíveis às qualidades (formais ou estruturais) propostas pelo autor. De uma certa maneira, a própria crítica também pode sonhar, também pode ser sonhadora.

Como dizia Che Guevara: "Há que endurecer, mas sem perder a ternura jamais". E nós acrescentamos: inclusive na crítica, da reflexão à amorosidade. Isto é, da reflexão propriamente crítica à reflexão docemente amorosa. Ken Parker, Batman/Coringa, Elizabeth/Alma: todos merecem a nossa estima e a nossa consideração. Entre a razão e a paixão. Sempre criticamente. Sempre amorosamente.

\begin{abstract}
Heroes and characters - maybe yes, maybe fiction. From the standpoint of the Libertarian Poeticalness, founded on the Marxist semiology and on the Bachelardian imaginary, the concreteness of characters is critically questioned, particularly of those present in comics. The culture of paranoia and narcissism is, thus, studied, as in the case of Batman/Joker. But the humanism of a Ken Parker is also analyzed. The world of comics is related to the language of movies and, in the end, a reflexion is offered, one that in being deeply critical, is equally loving. Within the limits of the Libertarian Poeticalness, of course.

Key words: Comics, Movies, Semiotics, Libertarian Poeticalness.
\end{abstract}




\section{Referências}

Bachelard, G. (1988). A poética do devaneio. São Paulo: Martins Fontes. Bachelard, G. (1989). A chama de uma vela. Rio de Janeiro: Bertrand Brasil.

Baptista, C. E. (1993). Dissertação do morcego. Dissertação de mestrado não-publicada, Curso de Mestrado em Comunicação, Escola de Comunicação da UFRJ, Rio de Janeiro.

Bergman, I. (1996). Imagens. São Paulo: Martins Fontes.

Berardi, G., \& Milazzo, I. (1994). Ken Parker: Os cervos \& Um hálito de gelo. São Paulo: Ensaio.

Brunoro, G. (1977). Corto Maltese ou la noblesse de l'aventure. In Les cahiers de la bande dessinée 32. Grenoble: Jacques Glénat (Dossier Hugo Pratt).

Cirne, M. (1975). Vanguarda: um projeto semiológico. Petrópolis: Vozes.

Cirne, M. (1982). Uma introdução política aos quadrinhos. Rio de Janeiro: Achiamé.

Cirne, M. (1983a). Para uma teoria materialista da vanguarda. In A biblioteca de Caicó. Rio de Janeiro: José Olympio.

Cirne, M. (1983b). Da vanguarda produtiva à semiologia materialista. In A biblioteca de Caicó. Rio de Janeiro: José Olympio.

Coma, J. (1979). Del gato Félix al gato Fritz: historia de los comics. Barcelona: Gustavo Gili.

Dias-Pino, W. (1971). Processo: linguagem e comunicação. Petrópolis: Vozes.

Duveau, M. (1975). Stan Lee et les Marvel comics. In Comics USA (pp. 41-51). Paris: Albin Michel.

Eco, U. (1970). O mundo de Minduim. In Apocalípticos e integrados (pp. 281-291). São Paulo: Perspectiva.

Fresnault-Deruelle, P. (1980). O espaço interpessoal nos comics. In. A. Helbo (Org.), Semiologia da representação. São Paulo: Cultrix.

Gaumer, P., \& Moliterni, C. (1994). Dictionnaire mondial de la bande dessinée. Paris: Larousse.

Horn, M. (Org.) (1976). The world encyclopedia of comics. Nova York: Chelsea House.

Jameson, F. (1994). Sobre a substituição de importações literárias e culturais no Terceiro Mundo: o caso da obra testemunhal. In Espaço e imagem. Rio de Janeiro: UFRJ Editora.

Kehl, M. R. (1986). Cinema e imaginário. In I. Xavier (Org.), O cinema no século. Rio de Janeiro: Imago.

Kothe, F. R. (1987). O herói. $2^{2}$ ed. São Paulo: Ática.

Leite, S. U. (1995). Konhecimento de Krazy Kat. In Jogos e enganos. Rio de Janeiro: 34 Literatura. 
Rey, A. (1978). Les spectres de la bande. Paris: Minuit.

Rosenfeld, A. (1995). Literatura e personagem. In A. Candido, \& A. Rosenfeld, A personagem de ficção. São Paulo: Perspectiva.

Sá, A. (1977). Vanguarda: produto de comunicação. Petrópolis: Vozes.

Short, R. L. (1968). The gospel according to Peanuts. $7^{\mathrm{a}}$ reimp. Nova York: Bantam.

Sontag, S. (1987). A vontade radical. São Paulo: Companhia das Letras.

\section{Notas}

${ }^{1}$ Este texto será parte do livro "Quadrinhos, sedução e paixão", a ser publicado brevemente pelo autor.

2 "Por realismo semiótico entendemos um dado trabalho exploratório, experimental, com a linguagem, ao nível de suas relações sociais, poéticas e textuais. Estas relações existem ideologicamente; cabe radicalizálas em seus efeitos críticos. Para o realismo semiótico, os signos concretos da linguagem são duplamente políticos: enquanto organizadores de um dado discurso e enquanto elementos que agenciam o social. Os signos, em sendo políticos, produzem leituras políticas quando trabalhadas em nível da pesquisa e da invenção. Por outro lado, produzem ou impulsionam leituras que devem ser situadas. O realismo semiótico encontra na semiologia materialista o seu principal suporte teórico-político, assim como encontra na vanguarda produtiva o seu principal agente prático-político" (Cirne, 1983, p.36). Cf. de igual modo: Cirne, 1983, p.12-22.

3 Sobre o poema/processo, cf. Sá (1977); Dias-Pino (1971); Cirne (1975). Decerto, pensar o poema/processo hoje, quase 30 anos depois de sua fundação, significa pensar em práticas que poderiam ter sido melhor trabalhadas na época (1967/1972), tais como dadaísmo/neoconcretismo ou, então, a relação conflitante marxismo/anarquismo. Aliás, a própria Poeticidade Libertária, por ser libertária, pressupõe o enfrentamento desses conflitos, exatamente nos campos teórico e crítico.

${ }^{4}$ Na verdade, o humanismo de Chaplin/Carlitos extrapola o próprio cinema. Por isso mesmo, Buster Keaton nos parece mais "cinematográfico": a sua cinemacidade existe a partir de uma dada linguagem, a linguagem dos signos concretos do cinema. Não que Chaplin não seja um grande autor; ele o é. Mas Keaton é mais cinema...

5 Ver indicação de Kehl, a Cultura do narcisismo, de Chistopher Lasch, São Paulo, Brasiliense, 1984.

${ }^{6}$ Em se tratando da relação perseguidor/perseguido, veja-se a pequena obra-prima de Robert Sheckley na área da ficção científica: "A sétima 
vitima", de 1953. (Este conto, no cinema, virou A décima vítima, de Elio Petri) registre-se também, nos quadrinhos, a relação Krazy Kat/ Ignatz Mouse, de George Herriman, estudada com brilhantismo por Sebastão Uchoa Leite (1995, p. 67-85). "Krazy Kat é a história de uma enigmática inversão, contada de mil formas através de numerosas obsessões temáticas" (p.68). Cf. de igual modo Javier Coma: "Meditação sobre a vida e a sociedade dentro de uma codificação poética extremamente sensível sobre o desamparo e o fracasso inerentes à condição humana, Krazy Kat proclama excepcionalmente a liberdade absoluta de um quadrinho, apesar de sua inserção na engrenagem da indústria" (1979, p. 48). Na ficção, em geral, e nos quadrinhos, em particular, a questão ficcional perseguidor/perseguido assume, ou pode assumir, características narrativas marcantes.

${ }^{7}$ Citando Kothe, no livro em pauta (1987): "Todo grande personagem é uma vilão de contrários ... Não há grande obra de arte que não una os contrários" (p. 13-14).

${ }^{8}$ Nomear os melhores filmes, os melhores discos, os melhores romances, os melhores poemas, os melhores quadrinhos, e assim por diante, é um exercício de pura imaginação criadora. A rigor, trata-se de uma curtição alimentada pelo ego (e, eventualmente, pela mídia). Nunca fugimos desse exercício, mesmo sabendo de sua relatividade crítica. Assim, os "nossos" melhores filmes, no dia 22 de dezembro de 1996, são os seguintes, depois de inúmeras (re)visões: 1. A aventura (Antonioni); 2 . Persona (Bergman); 3. A regra do jogo (Renoir); 4. Ano passado em Marienbad (Resnais); 5. Cidadão Kane (Welles); 6. A grande ilusão (Renoir); 7. Hiroshima, meu amor (Resnais); 8. O deserto vermelho (Antonioni); 9. Deus e o diabo na terra do sol (Gláuber Rocha); 10. O homem da câmera (Vertov); 11. Eclipse (Antonioni); 12. Morangos silvestres (Bergman); 13. Pierrot le fou (Godard); 14. O tesouro de Sierra Madre (Huston); 15. Desencanto (Lean); 16. Sherlock Jr. (Keaton); 17. O encouraçado Potemkin (Eisenstein); 18. Outubro (Eisenstein); 19. A paixão de Joana d'Arc (Dreyer); 20. O grito (Antonioni); 21. A marca da maldade(Welles); 22. Paixão dos fortes (Ford); 23. Viver a vida (Godard); 24. Othello (Welles); 25. A bela intrigante (Rivette). E mais: 26. Oleopardo (Visconti); 27. Oito e meio (Fellini); 28. Contos da lua vaga (Mizoguchi); 29. 2001: uma odisséia no espaço (Kubrick); 30. As férias do Sr. Hulot (Tati); 31. Um cão andaluz (Buñuel); 32. Era uma vez em Tóquio (Qzu); 33. Vertigo (Hitchcock); 34. Rashomon (Kurosawa); 35. One plus one (Godard); 36. Crônica de Ana Madalena 
Bach (Straub); 37. La hora de los hornos (Solanas); 38. No tempo das diligências (Ford); 39. Oterceiro homem (Reed); 40. Em busca do ouro (Chaplin); 41. Vidas secas (Nelson Pereira dos Santos). E os "nossos" melhores quadrinhos? Entre as séries, apontamos: 1. The Spirit (Eisner); 2. Little Nemo (McCay); 3. Krazy Kat (Herriman); 4. Corto Maltese (Pratt); 5. Valentina (Crepax); 6. Philémon (Fred); 7.Ken Parker (Berardi \& Milazzo); 8. Zeferino (Henfil); 9 . Flash Gordon ( Raymond); 10. Mr. Natural (Crumb); 11. Ferdinando (Capp); 12. Tarzan (Hogarth); 13. Steve Canyon (Caniff); 14. Paulette (Wolinski \& Pichard); 15. Bianca (Crepax); 16. Pererê (Ziraldo); 17. Cocco Bill (Jacovitti); 18. Urbanóides (Lapi); 19. Fantasma (Falk \& Moore ); 20. Os anti-heróis de Feiffer. Há, de igual modo, as estórias isoladas (e/ou "novelas gráficas") que merecem ser lembradas de forma especial: Arzach (Moebius); Bloodstar (Corben); Viagem a Tulum (Fellini \& Manara); Lanterna mágica (Crepax); Den (Corben); Saga de Xam (Rollin \& Devil); V de Vingança (Moore \& Lloyd); Watchmen (Moore \& Gibbons); Um contrato com Deus (Eisner) e Fragmentos completos (Luiz Gê), além de HP e Giuseppe Bergman (Manara); O segredo do Licorne, com Tintim (Hergé); Elektra assassina (Miller \& Sienkiewicz); Emmanuelle (Crepax); Sandman: o som de suas asas (Gaiman \& Dringenberg/Jones III); Sin City - Cidade do pecado (Miller); Desgraçados (Lourenço Mutarelli,); O Cavaleiro das Trevas (Miller); A piada mortal (Moore \& Bolland; Sonhar talvez... (Manara).

9 O corte gráfico implica necessariamente um corte espácio-temporal: o corte que impulsiona toda e qualquer narrativa quadrinhística. Este impulso se torna maior, se torna mais concreto, no último corte de uma página ímpar, possibilitando, se for o caso, uma surpresa qualquer na continuidade temática da estória. Como já dissemos antes, o corte gráfico passa por um entendimento semiótico que aponta para a especificidade dos próprios quadrinhos.

${ }^{10}$ Uma definição típica para o anti-herói, feifferiano pode ser esta: “... o abjeto Bernard Mergendeiler, um trapo psicológico devorado por tiques e complexos" (Horn, 1976, p. 244).

${ }^{11}$ Além de Sebastião Uchoa Leite e Javier Coma, citados na nota 5, outros estudiosos se voltaram com perspicácia crítica para Krazy Kat, entre os quais Alain Rey (1978, p. 96-104). De Alain Rey: "Mestre do paradoxo - e não do absurdo -, George Herriman, inimitável, não teve continuador; mas o renascimento do gênero, depois de 1960, é tributário de seu gênio" (p. 104). 
12 "Psicologicamente, ele tem os mesmos problemas de seus leitores. Talvez seja por isso que ele é um dos personagens mais populares das histórias-em-quadrinhos", como observou Stan Lee, seu criador (cf. Gaumer \& Moliterni, 1994, p. 586). Sem dúvida, Homem-Aranha se identifica bastante com alguns dos principais problemas do adolescente e mesmo do jovem adulto: instabilidade emocional, insegurança profissional, e assim por diante. Sobre o universo Marvel vale a pena consultar Duveau (1975).

13 "'O herói, em si, a rigor, por sua ambigüidade grave, por sua profunda humanidade, nos lembra o célebre personagem de Conrad 'Lord Jim', ator atormentado do romance de mesmo nome" (Brunoro, 1977, p. 27). Sobre Corto Maltese, escrevemos: "A série de Pratt, com seus graves tons másculos pautados no rigor das imagens, contém uma fluência narrativa que nasce feminina e se desdobra, quadro a quadro, plano a plano, entre o feminino e o masculino. Decerto que Corto Maltese é um personagem viril! O feminino, aqui, estará antes no espaço branco, vazio, que recobre as diversas ligações entre as imagens: marcação imaginária preenchida pelo leitor. Sim, Corto Maltese rompe com a fantasia alienante, modelo e sintoma dos quadrinhos mais conservadores. Que a nossa leitura, pois, recorrendo a Bachelard, não seja uma leitura inerte. (...) Entre seus críticos mais entusiastas, leiamos Gianni Brunoro, que escreveu em 1977, ao analisar a grafia da aventura em Corto Maltese (no artigo supracitado): "quadrinho de um realismo vigoroso aberto ao compromisso social consciente dos temas eternos da liberdade do homem e da dignidade de todo ser vivente. Um perfeito epígono dos grandes temas da aventura" (Cirne, 1982, p. 67-68).

Moacy Cirne estudou Direito na Universidade Federal do Rio Grande do Norte. Atualmente é professor adjunto do departamento de Comunicação Social da Universidade Federal Fluminense. Endereço para correspondência: Caixa Postal 65082, 20072-970, Rio de Janeiro, RJ. 